\title{
ARMLOCK IN THE CLOSED GUARD: KINEMATIC CONSEQUENCES TO THE KINETICS OF THE TECHNICAL GESTURE
}

\author{
Presented for the first time at II Brazilian National Symposium of Martial Arts and Combat \\ Sports, October 2016
}

\begin{abstract}
The present work had for objective to analyze the technical Brazilian Jiu-Jitsu gesture known as Armlock, wich was executed from the Closed Guard aiming at the identification of the body interactions resulted from its execution under a kinesiological view. It could be perceived that the opponent does not figure only as target, taking into account that he is understood as a necessary implement to accomplishment of the own blow that reached him, so that it was reputed essential taking also him as an axis of movement through which it's possible one to articulate and attain, thus, an ideal angle from which it is viable the lever is completed and, consequently, the attack can be consummated. The methodology employed in this study includes the utilization of resources of filming, photography, pictures and softwares, from which it was possible the rationalization of the proceedings adopted in this analysis.
\end{abstract}

Keywords: Brazilian Jiu-Jitsu, Armlock, technical gesture, kinesiology, kinematics, kinetics, sport optimization

\section{Introduction}

In spite of its rapid growth over the past decade (Arruda; De Souza, 2014), the Brazilian Jiu-Jitsu (BJJ) has not appeared much as an object of study in the Motricity Science field. Although the professional fighters have presented a considerable technical evolution and a global market has been created for this martial art, involving a variety of niches, such as fight wear and even media resources - not restricted to DVDs about techniques, but also including television channels and programs strictly related to jiu-jitsu - however, the 
significant lack of scientific production still remains. Paradoxically to its evolution in the sport field, the BJJ still presents a shortage of scientific literature (Andreato, 2010).

In a certain way, this can be explained by the motor complexity of jiu-jitsu, as well as by inherent factors connected to it, such as its acyclic nature and its difficulty to predict a counteroffensive reaction of the opponent (Brasil et al., 2015), which added to the need of a technological apparatus for carrying out the research, make it complex to be studied, leading the studies to develop in matters related to physical conditioning, physiological variables, anthropometric standards; although these also require specific tools for their implementation, they are more feasible, since they do not face as many barriers as biomechanical researches. In his article reviewing the biomechanical methods applicable to the Martial Arts study, Fernandes et. al., (2011) were able to conclude that most of the studies investigated were about purely descriptive researches, not being driven directly to the technical improvement of practitioner.

Regarding to the motor aspects of BJJ, this difficulty is furthermore accentuated, given the few approaches to the subject. This may seem contradictory, since it is really contrary to the significant technical evolution of athletes over the past few years, that which can be easily inferred from the increasingly high quality level of World Championships with a glimpse into the athletes' performance, one can realize the improvement in the manner to fight, in order to seek victory by submission (Jacaré, 2008).

Unlike the technical gestures of other combat sports that can be isolated, decomposed and studied in their respective planes and axes, without great difficulty, in BJJ, due to the multiplicity of interactions with the opponent, which is not limited to sequences of preordered blows (D'Avila, 2014), the kinesiological analysis becomes rather complex, since it tends to develop in a multifaceted way. When applying a particular technical gesture, the attacker interacts with your opponent on several axes, often simultaneously. Here arises the difficulty to isolate the gesture only in a certain plane to analyze it, which is a problem that tends to be aggravated in the enormous plasticity of BJJ, which has as a corollary its adaptability with regards to the individual conditions of the practitioner, from which result many variations that can be verified in the technical gestures of the modality, which, in its turn, complicate, in a certain way, the identification of ideal motor patterns, since they can change depending on the adaptations promoted in technique by practitioner in order to adapt 
it to his own potentialities. According to Gracie (2006), "there is a limited number of basic techniques, but there are endless variations".

Beyond the multiple possibilities of execution of technical gestures, there is not a specific type of subject required for their accomplishment as, for example, in performance sports like Gymnastics and Swimming, which are strongly influenced by the athletes' somatotype (Joao; Filho, 2015) (Hebbelinck et al., 1975 ), and may therefore be established a technical connection with strict anthropometric paradigms to impact directly on their own performance. However, it has not stated here that the anthropometric standards are destitute of relevancy in the BJJ, and that they do not influence in any way the kinetic chain of technical gestures, but, since this art is configured for the benefit of the weakest players (Rufino; Darido , 2009), they have the chance to adapt the technical for themselves and, frequently, to render it even more effective because their lack of vigor requires of them, on the other hand, a greater technical improvement to compensate it, requiring, thus, other skills that impact positively on the (re) configuration of the gesture.

However, this does not imply to exhaust the issue within the possibilities of each individual. Although it is considered that the technique is influenced by the physical conditions of the each subject and may possibly be adapted according to them, this paper will objectively seek evidencing how to perform the Armlock technical gesture, describing it over its kinematics and identifying the angle from which the full employment of kinetic sources of the Armlock's lever is possible, i.e., from which angle all the muscles involved in the accomplishment of the submission can effectively operate, which can be translated into an objective function in terms of a biomechanical optimization of technical gestures.

The Armlock is a blow that aims to neutralize the opponent, causing a trauma in their elbow joint, at the same time making him unable to attack and even more vulnerable in his defenses. Its mechanism consists of a movement of hyperextension from which the joint is forced beyond its normal limits, it is possible through the combination of tractive forces of the upper limbs with lower limbs in synergism with the trunk. According to Park (2008), the most recurrent traumas are triggered on the joint capsule, as well as the structures of the collateral ligaments.

There are so many Armlocks as there are endless possibilities of Soft Art, in this paper the Armlock in Closed Guard will be approached, which is, for Gurgel (2000), "one of 
the places with more chances for submission". As for Trindade (2001), besides being the most emblematic blow in BJJ, a glimpse into its composition allows to identify a "perfect geometry with levers and points of support with millimetric precision".

\section{Materials \& Methods}

In this paper it is possible to identify interpenetration between Kinesiology and Biomechanics, as well as between Kinematics and Kinetics. The opponent was taken as a movement axis and the analysis of the movement occurred predominantly from the transverse plane. If the grappler's muscle action was described by taking as basis his joint movement in its respective planes, his movement has also been described in relation to his trajectory on the opponent's axis (kinematics), reaching a space positioning from which it is possible the connection of all forces involved in the finishing lever (Kinects).

Finding an ideal angle from which it is possible to maximize the rational effort of muscles and minimize the external parasitic forces is a typical optimization of cyclic sports (Sacripanti, 2016). However, despite the fact that Brazilian Jiu-Jitsu fits in the group of Sports of Dual Situation and taking in consideration that the objective function of this group should not only be to minimize the effort, as well as to maximize efficiency, it is considered necessary to achieve a certain spatial arrangement so that the attacker can fully use all the skeletal muscles required to perform the technique. In other words, the application of this technical gesture calls for a spatial positioning so all muscles can be recruited on the improvement of the lever, that which can be better understood through the relation between angular and linear movements (Hamill, 1999) This can be evidenced by comparing the symmetry of the vector composition in Figure 1, as well as the angular displacement $(\Delta \Theta=$ $\left.\Theta_{\text {final }}-\Theta_{\text {initial }}\right)$ and linear displacement $(\Delta \mathrm{S}=\mathrm{R} \times \Delta \theta)$ of the hip explained in Table 1, with the symmetry in Figure 2. 


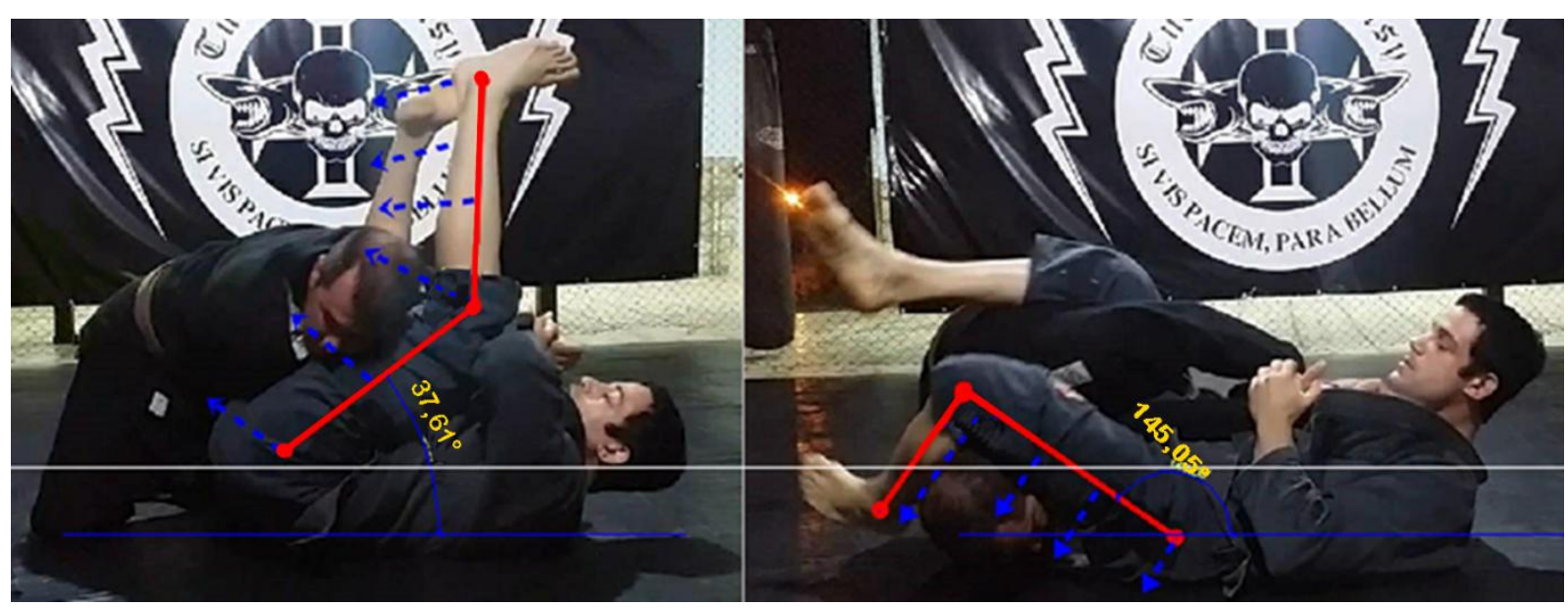

Figure 1: Vector action of the lower limb in the kinetic chain of the Armlock technical gesture and vision of the initial and final angle (view of the frontal plane).

Table 1 - Angular and linear displacements of the kinetic source (hip/thigh) of the armlock technical gesture's lever

\begin{tabular}{lcc}
\hline \multicolumn{1}{l}{ Initial Angle } & $\theta 1$ & $37.61^{\circ}$ \\
Final Angle & $\theta 2$ & $145.05^{\circ}$ \\
Angular Displacement (degree) & $\Delta \theta=\theta 2-\theta 1$ & $107.4^{\circ}$ \\
Angular Displacement (radian) & $\Delta \theta=\theta 2-\theta 1$ & 1.875 \\
Radius (meter) & $\mathrm{R}$ & 0.47 \\
Linear displacement (meter) & $\Delta \mathrm{S}=\mathrm{R} \times \Delta \theta$ & 0.88
\end{tabular}




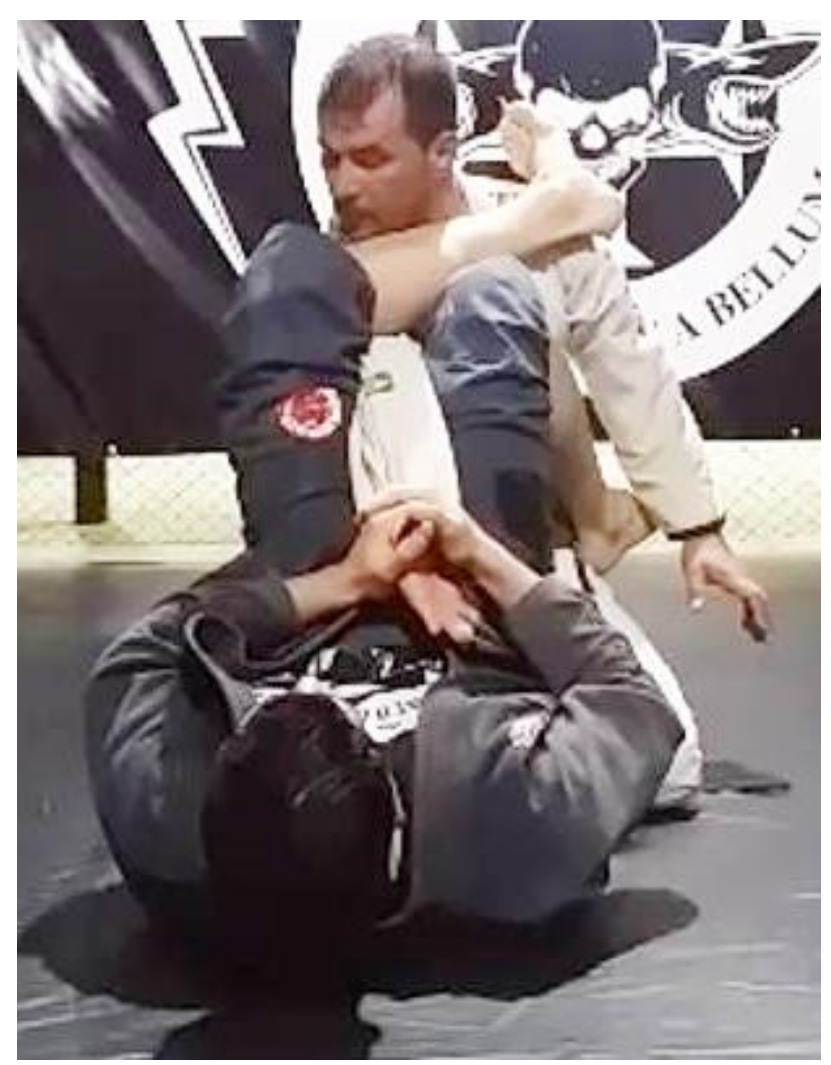

Figure 2: Armlock's lever deprived of one of its kinetic sources due to the absence of angular displacement (view of the frontal plane).

From the spatial position seen in Figure 2, it remains explicitly patent the impossibility of the hip exerting a dynamic role in the lever, since it is synergistically extended with the flexed knee so as to press the opponent's head toward the mat in the process of hyperextension of his elbow. In this inadequate spatial arrangement, the hip is lying externally rotated and slightly abducted, the hip cannot be combined with the trunk and be extended.

Despite actions of biceps flexion, shoulder adduction, contraction of dorsal muscles and trunk extension are possible, the action of the hip is impaired, consequently compromising the kinetic chain of the movement, making the lever less powerful, but the finishing is still possible if there is an effective adjustment of the elbow, enabling hyperextension of it (as can be seen in Figure 2). But once the consumption of this attack occurs through a complex movement, requiring the combination of several tractive forces to execute the lever, if a previous angular displacement is not performed, the attacker cannot use all the kinetic sources involved in the technical gesture and therefore does not get the same accuracy. An Armlock struck in these circumstances, although not inept at all, does not have the same damaging potential as those carried out from a perfect angular positioning. 
From the perspectives of frontal, sagittal and transverse planes, using a GoPro camera to capture images while performing the pendulum movement in the Closed Guard, it was identified the movement axis that allows reaching the lever zone of Armlock, that is, the longitudinal axis, located in the lumbar spine of the opponent. However, other parts of the opponent's column move when his posture is broken, which, added to a rotation on his own axis, due to the pressure on his neck by the lower segments, culminate in an angular displacement of the opponent, as it can be seen in Figure 5.

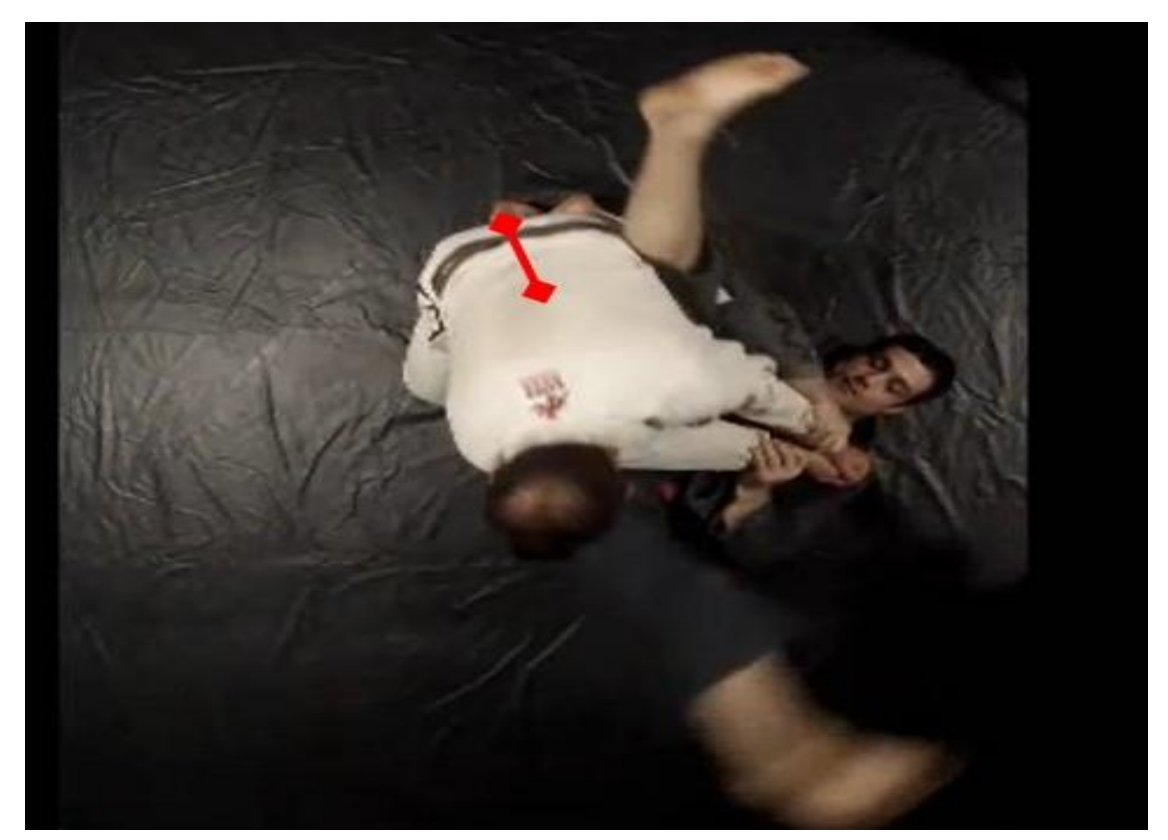

Figure 3 - Identification of the longitudinal axis from the transverse plane by execution of the pendulum movement in the Closed Guard, where the three run modes were performed, being the starting point of three variations.

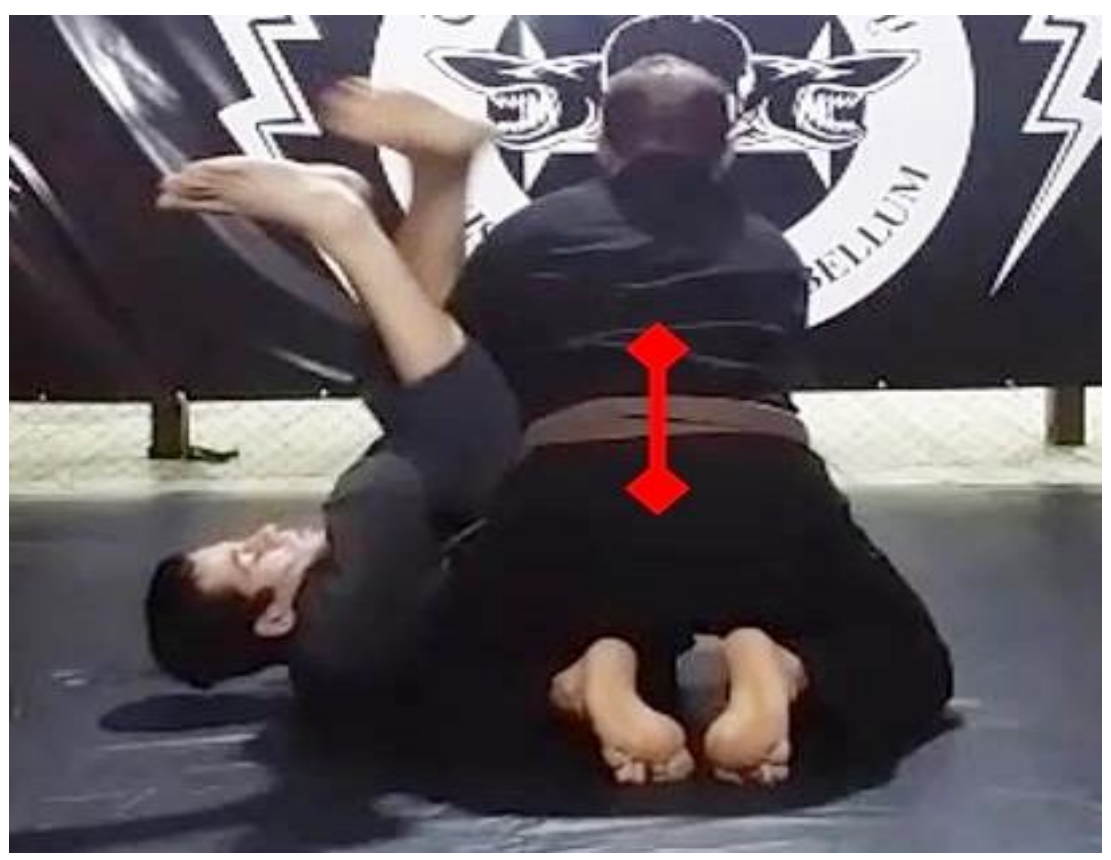


Figure 4 - View of the longitudinal axis from pendulum movement in the frontal plane.

The action was done in three different ways, by a pair of BJJ practitioners with an average height of $1.76 \mathrm{~cm}, 82 \mathrm{~kg}$ and technical proficiency adequate for levels of black belt and brown belt. The analysis was developed as follows. From the filming converted into slow motion by Sony Vega Pro13 software, several photos were extracted to show different angles of the movements that were measured using AutoCad software, which in turn allowed the calculation of the angular displacement $\left(\Delta \Theta=\Theta_{\text {final }}-\Theta_{\text {inicial }}\right)$ of the three Armlocks Run Modes in the Closed Guard. Then the values were transferred to a Microsoft Excel spreadsheet and converted into radians and multiplied by the radius value (measured with an extended tape, from the head of the attacker to the hips proximal end, i.e., until the opponent axis, therefore allowing us to find the linear displacement traveled $(\Delta S=R \times \Delta \theta)$.

\section{Results \& Discussions}

The First Run Mode was accomplished putting the foot at the waist of the opponent to tilt the trunk and therefore to obtain the angle that enables the lever, allowing the hips to extend concomitantly with synergistic action of the other body segments. The attacker's angular displacement verified $(\Delta \theta)$ was of $67.5^{\circ}$ in his trajectory until the lever zone (Figure 5). However, the attacker was not the only one to move, the opponent also presented a displacement around $16.44^{\circ}$. The total displacement was of $83.94^{\circ}$, a result of the opponent's displacement added to the attacker one. It is also possible to identify a linear displacement of $1.4 \mathrm{~cm}$, as shown in Table 2 . 


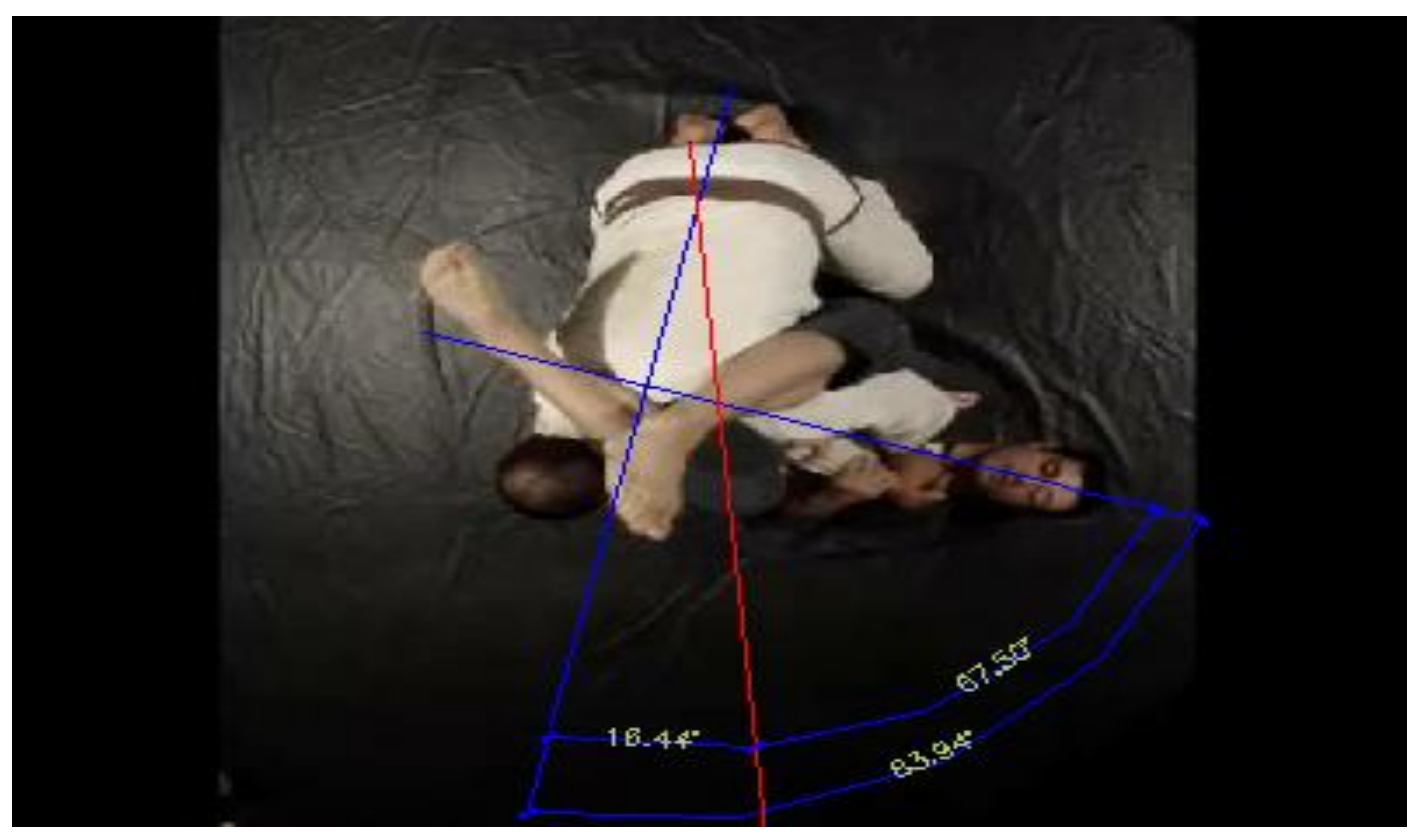

Figure 5 - Angular displacement of the first run mode of Armlock technical gesture.

Table 2 - The First Run Mode

\begin{tabular}{lcc}
\hline Initial Angle & $\Theta 1$ & $0^{\circ}$ \\
Final Angle & $\Theta 2$ & $67.5^{\circ}$ \\
Angular Displacement (degree) & $\Delta \Theta=\Theta 2-\Theta$ & $67.5^{\circ}$ \\
Angular Displacement (radian) & $\Delta \Theta$ & 1.18 \\
Radius (meter) & $\mathrm{R}$ & 0.88 \\
Linear Displacement (meter) & $\Delta \mathrm{S}=\mathrm{R} \times \Delta \theta$ & 1.04 \\
\hline
\end{tabular}

The Second Run Mode of the technical gesture was carried out from the pendulum movement, hugging the leg on the side to which the rotational movement is performed, as the Grand Master Hélio Gracie lectured, in his book Gracie Jiu-Jitsu (turning Armlock). The second one presented the most significant displacement. A total displacement of $116.42^{\circ}$, with $\Delta \theta 100.46^{\circ}$ for the grappler and $15.97^{\circ}$ for the opponent (Figure 6). It was also possible to identify the linear displacement trajectory $(\Delta \mathrm{S})$ of $1.54 \mathrm{~cm}$, as shown in Table 3. 


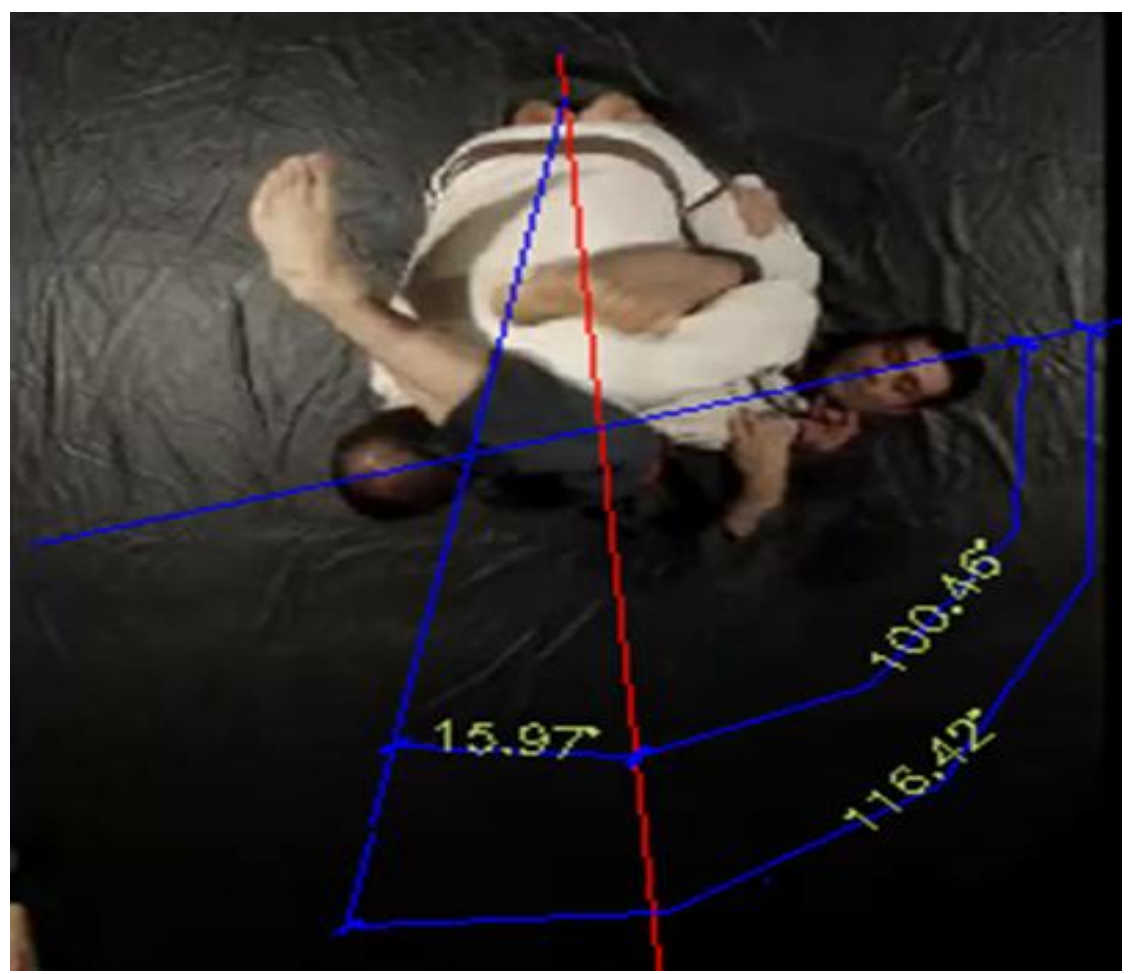

Figure 6 - Angular displacement of the Second Run Mode of the Armlock technical gesture.

\begin{tabular}{lcc} 
Table 3 - Second Run Mode & & \\
\hline Initial Angle & $\Theta 1$ & $0^{\circ}$ \\
Final Angle & $\Theta 2$ & $100.46^{\circ}$ \\
Angular Displacement (degree) & $\Delta \Theta=\Theta 2-\Theta$ & $100.46^{\circ}$ \\
Angular Displacement (radian) & $\Delta \Theta$ & 1.75 \\
Radius (meter) & $\mathrm{R}$ & 0.88 \\
Linear Displacement (meter) & $\Delta \mathrm{S}=\mathrm{R} \times \Delta \theta$ & 1.54 \\
\hline
\end{tabular}

Finally, the Third Run Mode was performed by climbing the guard. This mode presented the shortest route until the lever zone, resulting in a total angular displacement of $43.63^{\circ}, \Delta \theta 30.5^{\circ}$ for the grappler, whereas the opponent also suffered less movement due to the striking action, $13.13^{\circ}$ (Figure 7). The lowest trajectory in terms of the linear displacement traveled $(\Delta S)$ was also identified, displaying a value much lower than the others: $0.47 \mathrm{~cm}$, according to Table 4 . 


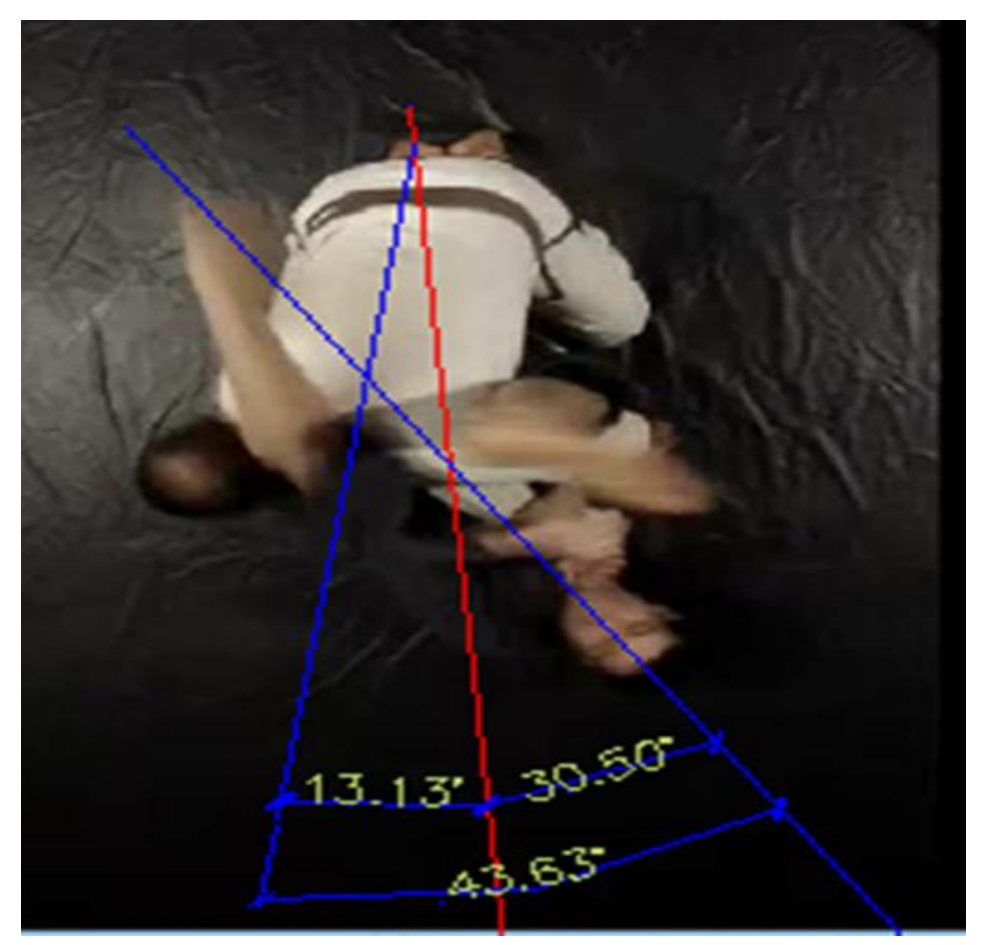

Figure 7 - Angular displacement of the Third Run Mode of the Armlock technical gesture.

Table 4 - Third Execution Mode

\begin{tabular}{lcc}
\hline Initial Angle & $\Theta 1$ & $0^{\circ}$ \\
Final Angle & $\Theta 2$ & $30,5^{\circ}$ \\
Angular Displacement & $\Delta \Theta=\Theta 2-\Theta 1$ (Degree) & $30,5^{\circ}$ \\
Angular Displacement & $\Delta \Theta$ (radians) & 0,53 \\
Radius & $\mathrm{R}(\mathrm{m})$ & 0,88 \\
Linear Displacement & $\Delta \mathrm{S}=\mathrm{R} \mathrm{x} \Delta \theta$ & 0,47 \\
\hline
\end{tabular}




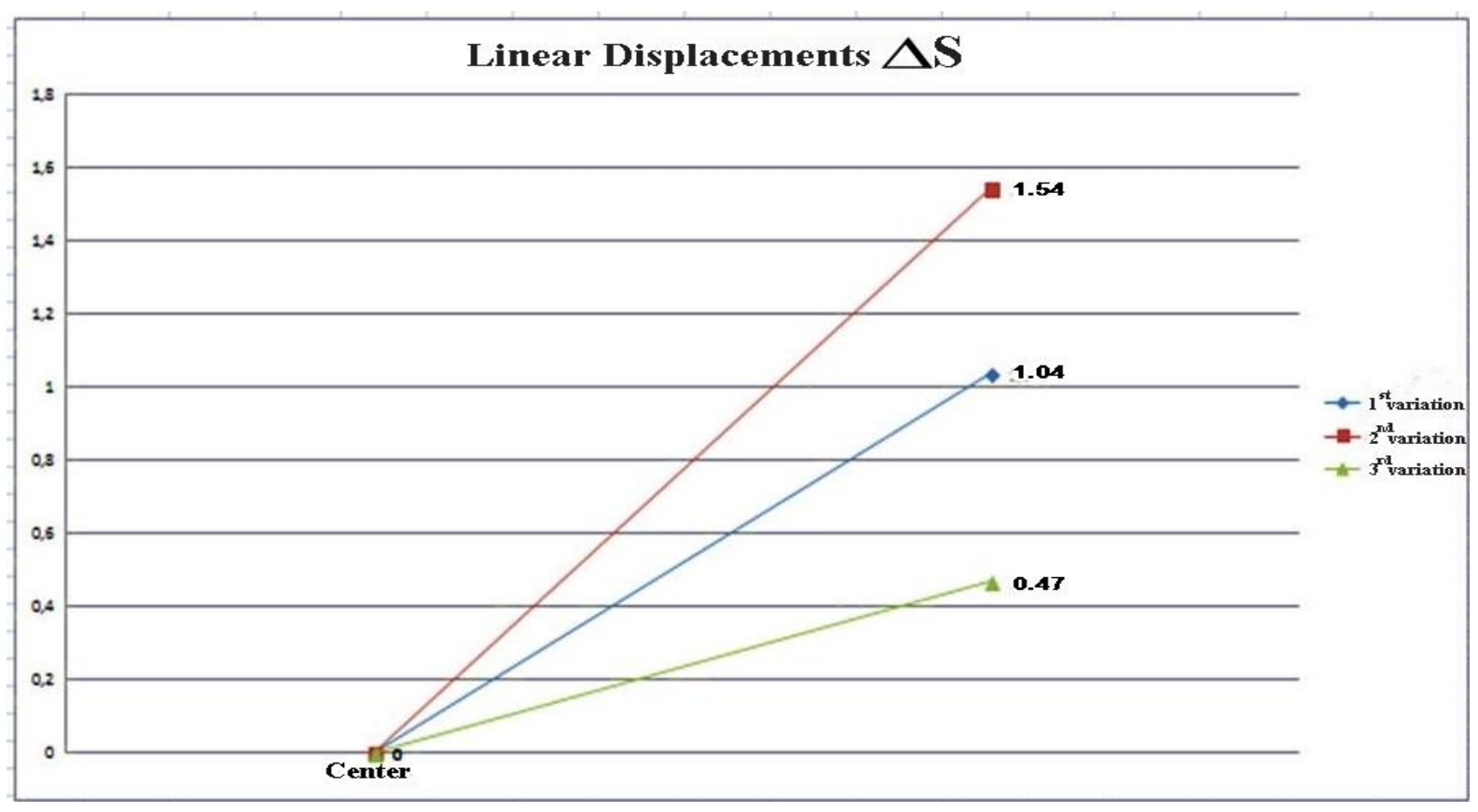

Figure 8 - Chart showing the linear displacement of the three Armlock Run Modes - the trajectory to the lever zone.

It was verified that the spatial arrangement in the Third Run Mode is a necessary and sufficient condition for the full employment of the muscles required by the movement, considering that the first two also allowed it, but only after performing a larger route. Performing the third one, the attacker tried to make as minimum displacement as possible, so that he could reach the lever zone with the least possible effort. Besides the trajectory can be able to imply in energy saving, an advantage in terms of safety for the grappler is also identified, since he keeps the open guard for a shorter period during his transition to the lever zone.

Considering the possibilities in terms of biomechanical optimization that derives from it, the Run Mode that presented a shorter trajectory was chosen to be described below; since it is in line with the biomechanical principle of "Minimum Effort for Maximum Efficiency", which has an impact on the Ne Waza of Judo and, therefore, it is also applied on BJJ, since it is derived from Judo, either totally or in part.

Whereas the joint movement of certain body segment corresponds to the anatomical action of a muscle (Correia et. al., S.d), the identification of the muscles involved in performing the technical gesture in question occurred through their comparison with the joint movement for which they are effectors. 


\section{Description of the Third Run Mode of the Technical gesture}

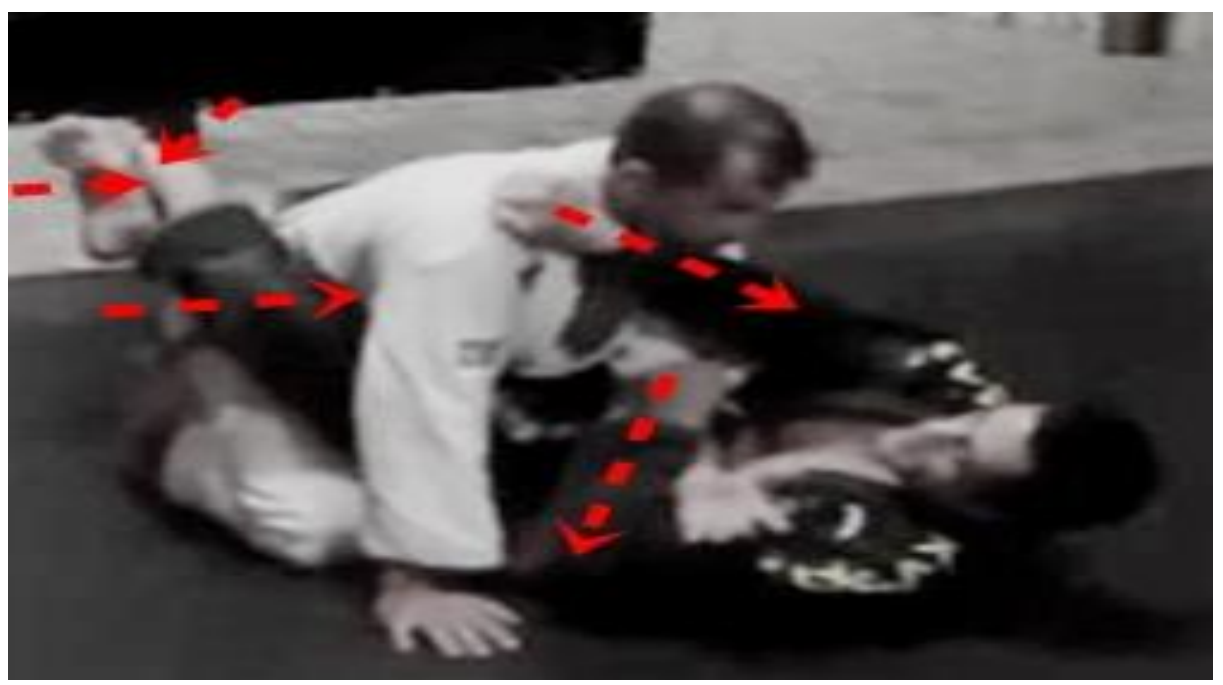

Figure 8 - Identification of grips and traction vectors.

Starting from the initial position in Closed Guard, when the atacker is located statically in a horizontal arrangement, while the opponent is vertically oriented, appearing not only as a target, but as an axis or set of axes disposed between the attacker's legs, crossed on his back, connecting through a crossing of his feet in dorsiflexion (carried out mainly by the Tibialis Anterior and Extensor Hallucis Longus).

The hips are in abduction and lateral rotation, in which it's possible identify the work of the medial adductors and hips flexors (Iliopsoas group). The flexors hips exert force on the opponent to lock him in the guard; whereas the Iliopsoas group exert traction on the opponent, at first a stabilizing traction to maintain the opponent close, and then a destabilizing traction to assist in breaking his posture.

The knees lie flexed, and the knee of the leg beneath the connection exerts a tension to extend itself, therefore recruiting the muscles of the quadriceps, while the leg where the foot is crossed over exerts a tension in order to flex itself and need mostly the hamstring muscles. It's possible to observe an inverse action between them, which can called the antagonist, to the maintenance of the Closed Guard.

Likewise, the trunk can be taken from the beginning in its active role, as this is an offensive position, not a rest one, that which implies, therefore, a corresponding muscle 
activity with offensiveness level that is required. In this way, a flexion of the cervical spine can be pointed out: sustained through isometric contraction of the neck muscles, especially from the action of the Sternocleidomastoid, Rectus capitis anterior, Longus colli, Longus Capitis; and the thoracic spine: effected by the contraction of Rectus Abdominis, aided by the Obliques (internal and external), which remain active in conjunction with other muscles of the trunk, as the Pectorals group contracted isometrically.

Once the viewing angle is achieved, based on the previous movements, it can be pointed out the movement of the upper limbs, positioned according to the grips (interphalangeal flexion associated with metacarpophalangeal flexion ) that has been done. To prevent the opponent defending himself by neutralizing the lever by flexing his elbow and applying a Rear Naked Choke on their own arm when the attack is triggered, the grappler places the grip not in the triceps region, but in the biceps one, next to the distal humeral epiphysis. Thus it is possible to reduce his defense possibilities by neutralizing his flexion.

By pulling the limb under attack through a pull in an oblique direction, the actions of muscles related to the joints of wrist, elbow, glenohumeral and scapulothoracic can be identified. Among forearm flexor muscles: it can be highlighted the action of Flexor Carpi Radialis and Flexor Carpi Ulnaris, beyond the Flexor Digitorum Superficialis, Flexor Digitorum Profundus and Palmaris Longus. Among arm muscles: Brachialis and Biceps flex the elbow joint whereas the scapulothoracic and glenohumeral joint motions are carried out by the dynamic work of the Deltoid and Trapezius.

To effectively control the opponent's elbow containing his flexion movement is not enough, it is necessary developing a kinesthetic awareness, so that the attacker can use his own navel as a sensor to inform the position of the opponent's elbow, so being able to effectively control him.

Bearing in mind the opponent's trunk control, in order to prevent him from executing the posture, neutralizing the climbing of the guard or that he dumps your weight on the attacker's body, that which would impair the extensor kinetic sources of lever (hips and trunk), the attacker applies another grip on the trapezius region of his shoulder girdle in a prone form, which, in addition to allowing a better control of his trunk, has a synergistic function to the rotation movement in the longitudinal axis of the opponent, acting synergistically on the trunk and lower limbs, so that it optimizes the lateral inclination 
making the body lighter, reducing the external parasitic forces that acting against performance (Sacripanti, 2016), which give him, consequently, more mobility enabling to achieve an oblique positioning from which the full consummation of attack is possible.

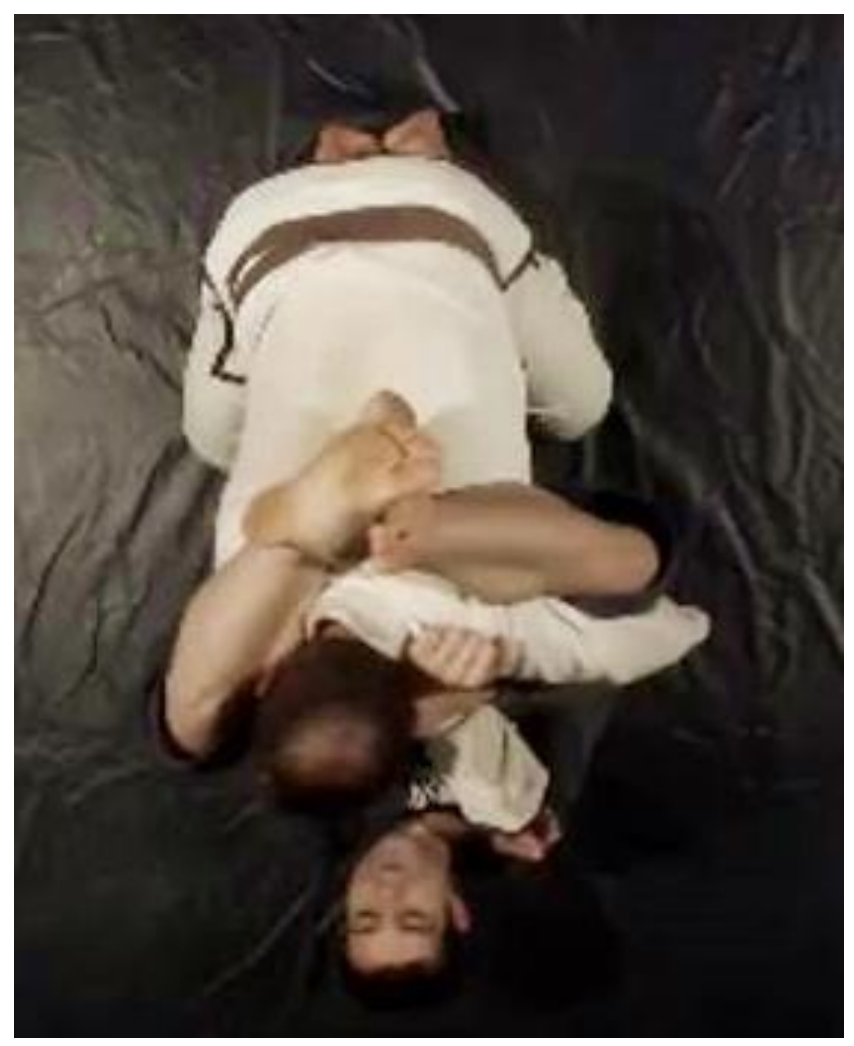

Figure 9 - Climbing the guard after the application of grips and breaking the opponent's posture

As soon as this spatial positioning - from where the attacker reaches a better angle for the accomplishment of attack - is achieved, the attacker continues to climb the guard, projecting the hips and elevating the trunk, so that he can cover the whole limb that he is attacking. It can provide not only an optimization of the position adjustment, but also prevent the opponent from the guard evades when one tries to pass the leg direct to apply the lever, when, then, the opponent suddenly get up as soon as he realizes that the guard was momentarily open.

Once the guard is climbed, the attacker continues extending the arm, putting a pressure on the neck of the opponent with the ulnaris face of the forearm; so as to prevent him to advance with his weight, the attacker passes the leg, replacing the grip to the wrist, which is tensioned with the upper limbs, accompanying an extension of hip and trunk, combined in a single kinetic chain. The performance of the lower limb in the kinetic chain is 
given especially by the action of the Gluteus Maximus, added to the action of the Hamstrings that, in addition to flex the knee, engage the limb on the opponent's neck region, helping in the hip extension process. The trunk, in turn, operates primarily through the Quadratus Lumborum together with the Spinal Erectors in an extension action.

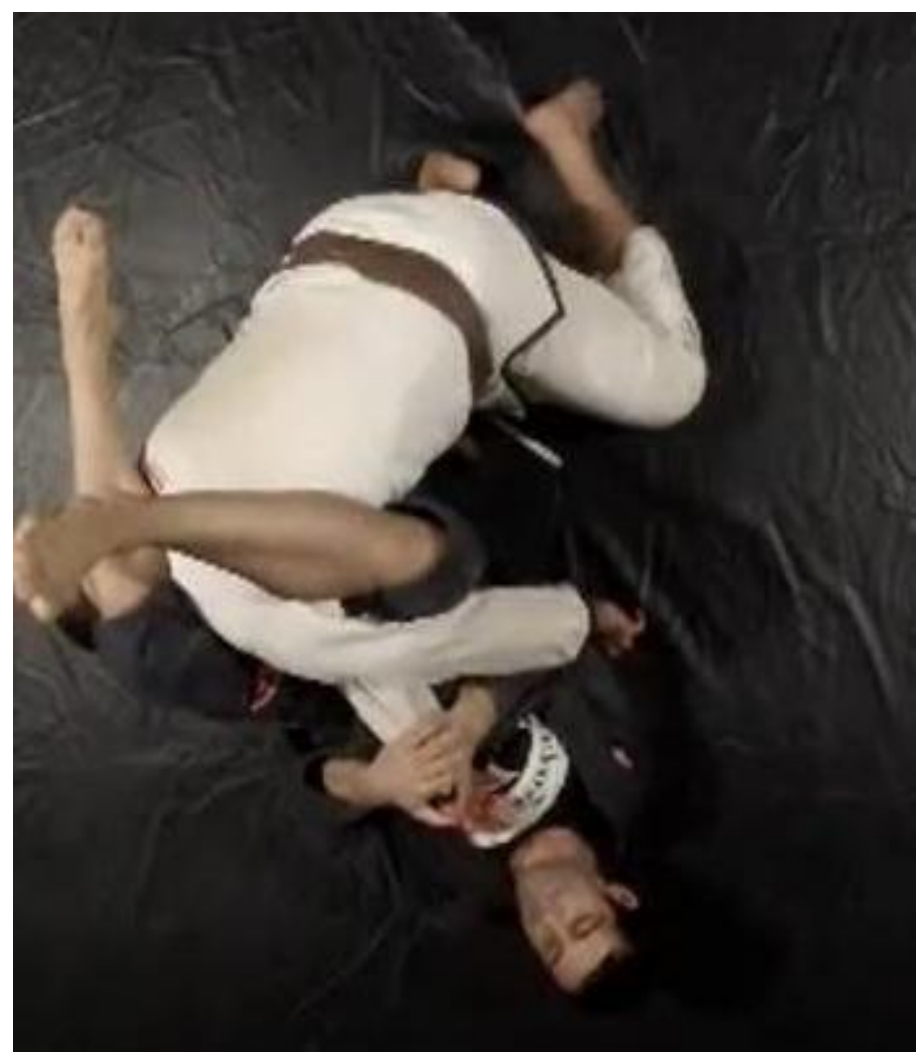

Figure 10 - Execution of the attack. 


\section{Conclusion}

Considering the multiple relations of interdependency between the attacker and the opponent, articulating both on himself and on his opponent, it was reached not only a kinesiological description of the Armlock, but also the rationalization of the entire kinematics of the technical gesture studied. Through the analysis of the recorded images, at first it was verified the need for angular displacement so that there is full employment of all kinetic sources involved in the lever of the blow, and from the quantification of the trajectory of the three Run Modes, it was possible to identify the mode in which the Armlock is liable to be optimized, since it presents the shortest distance until the lever zone, that which can result not only in advantages in terms of energy saving, but also in terms of safety for the attacker, enabling him to perform the transition without expose himself too much, when he open his own guard to reach the lever zone. Far from exhausting the subject, one expects to have contributed to further studies, accordingly, adapting to the lack of theoretical references and taking advantage of the best possible form of empirical knowledge of the Masters and Sport Coaches, without, however, imply the abstraction of the opponent, which, constituting a component of the own gesture, is fundamental to its perfect intelligibility. 


\section{References}

1. Alberton, C. L.,Brasil, B., Chiviacowsky, S., Del Vecchio, F. B. (2015). Comparison of dynamic balance between Brazilian Jiu-Jitsu practitioners with different levels of experience. Revista Brasileira de Educação Física Esporte, 29(4), 545-551. doi: $\underline{10.1590 / 1807-55092015000400535}$

2. Andreato, L. V. (2010). Bases for prescription in sports training aplicateded to Brazilian Jiu-Jitsu. Revista da Faculdade de Educação Física da UNICAMP, 8, (2), 174-186. Retrieved from:

http://periodicos.sbu.unicamp.br/ojs/index.php/conexoes/article/view/8637749/5440

3. Arruda, P. D., Souza, B. J. (2014). Jiu-Jitsu: a methodological approach related to the broken of the stereotype. Revista Redfoco, 1 (1), 67-89. Retrieved from: http://www2.uern.br/index.php/redfoco/article/viewFile/954/518

4. Carter, L., De Garay, A., Hebbelinck, M. (1975). Body Build and somatotype of Olympic swimmers, divers and water polo players. In: J. P. Clarys \& L. Lewillie (eds.), Swimming II, pp. 285-305. University Park Press, Baltimore. Retrieved from: https://www.iat.uni-leipzig.de/datenbanken/iks/open_archive/bms/2_285305_Hebbelinck.pdf

5. Correia, P. P., Freitas, S., Oliveira, R. (S.d.). Estudo do Movimento. Retrieved from: http://www.fmh.utl.pt/indices/estudomovimentop.pdf

6. Darido, S. C., Rufino, L. G. B. (2009). Initial considerations about Brazilian Jiu-Jitsu and its implications to the pedagogic practice. Congresso Paulistano de Educação Física Escolar. Retrieved from:

https://www.researchgate.net/publication/280444899_Consideracoes_iniciais_sobre_o_ji u_jitsu_brasileiro_e_suas_implicacoes_para_a_pratica_pedagogica

7. D’Avila, L. (2014) Interview. BJJPix. Retrieved from: http://www.bjjpix.com/index.php/pt/11-jiu-jitsu/490-leo-d-avila-sobre-a-ibjjf-a-atos

8. Fernandes, F. M., Wichi, R. B., Silva, V. F., Ladeira, A. P. X., Ervilha, U. F. (2011). Biomechanical methods applied in martial arts studies. Journal of Morphological Sciences, 28 (3), 141-144. Retrieved from: http://jms.org.br/PDF/v28n3a01.pdf

9. Filho, J. F., Joao, A. F. (2015). Somatotype and Body Composition of the elite brazilian gymnasts. Science of Gymnastics Journal. 7 (2), 45-54. Retrieved from: file:///C:/Users/Usuario/Downloads/SCGYM_7_2_2015_journal.pdf

10. Gracie, H. (2006). Gracie Jiu-Jitsu. (1 ${ }^{\text {st }}$ ed.). São Paulo: Saraiva.

11. Gurgel, F. (2000). Manual do Jiu-Jitsu: Básico. (1 ${ }^{\mathrm{a}}$ ed.).(Vol. 1). Rio de Janeiro: Axcel Books do Brasil. 
12. Hamill, J; Knutzen, K. M. (1999). Bases Biomecânicas do Movimento Humano. (1 ${ }^{\mathrm{a}}$ ed.). São Paulo: Manole.

13. Jacaré, R. (2008, Março 15). Interview. Revista Tatame. Retrieved from: http://www.tatame.com.br/tatame/romero-jacare

14. Park, J. H. (2008). Elbow Pain. Figth Magazine. Retrieved from: http://www.fightmagazine.com/elbow-pain-334

15. Sacripanti, A. (2016). Biomechanical Optimization of Judo. Cornell University Library. Retrieved from: https://arxiv.org/abs/1604.08390

16. Trindade, I. M. (2012, Dezembro 13). Missão Armlock. Revista GracieMag, 190, 38-46. 